\title{
The distinctive vertical heterophoria of dyslexics
}

\author{
Patrick Quercia ${ }^{1,2}$ \\ Madeleine Quercia ${ }^{3}$ \\ Léonard J Feiss ${ }^{3}$ \\ François Allaert ${ }^{4}$ \\ 'Department of Ophthalmology, \\ University Hospital, ${ }^{2}$ INSERM U I093, \\ University Bourgogne Franche-Comté, \\ Dijon, ${ }^{3}$ Office of Ophthalmology, \\ Beaune, ${ }^{4}$ CEN Biotech, Dijon, France
}

Correspondence: Patrick Quercia Office of Ophthalmology, 15 rue du Clair Matin, F-2I 200 Beaune, France

Tel +33380246874

Fax +33 38024 II 39

Email docteur.quercia@neuf.fr
This article was published in the following Dove Press journal:

Clinical Ophthalmology

25 September 2015

Number of times this article has been viewed

Abstract: In this study, we looked for the presence of vertical heterophoria (VH) in 42 dyslexic children ( 22 males and 20 females) aged 118.5 \pm 12.9 months who were compared with a control group of 22 nondyslexic children (eleven males and eleven females) aged 112 \pm 9.8 months. Dyslexics presented a low-level (always $<1$ prism diopter) VH combined with torsion. This oculomotor feature clearly separates the dyslexic group from the normal readers group. It is independent of the type of dyslexia. The essential feature of this $\mathrm{VH}$ is a lability that appears during specific stimulation of sensory receptors involved in postural regulation. This lability is demonstrated using a vertical Maddox test conducted under very specific conditions in which postural sensors are successively stimulated in a predetermined order. A quantitative variation in this VH may be seen during the Bielchowsky Head Tilt Test, which reveals hypertonia of the lower or upper oblique muscles. Vertical orthophoria can be achieved by placing low-power prisms asymmetrically within the direction of action of the superior or inferior oblique muscles. The selection of power and axis is not only guided by elements of the eye examination but also from observation of postural muscle tone. All these elements suggest that the VH could be of postural origin and somehow related to the vertical action of the oblique muscles. VH and torsion are not harmful per se. There is no statistical relationship between their level and the various parameters used to assess the reading skills of dyslexic children. $\mathrm{VH}$ and torsion could be a clinical marker of global proprioceptive dysfunction responsible for high-level multisensory disturbances secondary to poor spatial localization of visual and auditory information. This dysfunction might also explain the motor disorders concomitant to dyslexia.

Keywords: dyslexia, proprioception, ocular torsion, postural control, oblique muscles, prism

\section{Introduction}

Reading is a complex oculomotor and cognitive activity whose exact mechanisms are still poorly understood. It is presumed to involve several steps that are conventionally separated into low-level and high-level processings. ${ }^{1}$ The first begins at the moment of visual capture of written words and stops at the beginning of character identification in the occipital lobe. Though beginning with the retinal capture of the written text and image transmission along the optic pathways, the process additionally involves specific competences of extrinsic and intrinsic eye muscles to ensure correct focus, saccades, and fixation. The second process, primarily cortical and cognitive and still poorly understood, corresponds to the semantic decoding of words and sentences. ${ }^{2}$

Several theoretical models have been proposed to describe the low-level process. . $^{1,4}$ This phase initially assumes that ocular fixation occurs precisely at a particular location of the word designated as the center of gravity. ${ }^{5}$ It is slightly displaced to the left relative to the geometric center of the word. It is the object of a motor-driven binocular retinal fixation associated with a cognitive-based focalization of attention. ${ }^{1,3}$ Despite the required accuracy, the visual axes are not precisely centered on this exact point and often leave a space of more than one character between them, which is in turn often accompanied by a slight vertical displacement. ${ }^{6}$ As soon as the partial decoding 
of the word appears to be sufficient enough to be completed without additional information, the focus of attention will transfer to the next word even though retinal fixation, subject to oculomotor constraints, remains on the center of gravity. This transfer of attention is probably guided by a parafoveal preview and could be the source of programing for the saccade requisite for binocular fixation on the next word. The process would thus continue in a serial fashion to enable decoding of the entire sentence. The automation and precision of the process would be gradually improved by the introduction of a cerebral lexicon as reading capacity increased. ${ }^{7}$ Oculomotor function and the cognitive processing of what has been read are therefore intimately entwined throughout the decoding and understanding of a text.

The precision of the position of the center of gravity and of the attention given during low-level processing intuitively leads to a need to understand the mechanisms that control visual-spatial location during reading. They certainly depend on the retinal projection of the center of gravity and also on the perception of the position of the eyes during decoding. ${ }^{8}$ This position is coded from the efferent oculomotor control information and from the afferent proprioceptive information originating in the eye muscles, without us really knowing the relative importance of each of these two elements. Ocular proprioception would be primarily used for error correction, as is necessarily the case when learning. ${ }^{9-11}$

Ocular proprioception's role may not be considered in isolation since it is integrated into the rest of the body's proprioceptive system. ${ }^{12,13}$ This proprioceptive coupling may in turn associate with multisensory feedback, notably of vestibular, stomatognathic, and cutaneous origin, to regulate postural control. ${ }^{14,15}$ Several studies have shown that it could be altered in children with developmental dyslexia. ${ }^{16-20}$ Dyslexia is a disruption in learning to read which is defined as "a specific learning difficulty that mainly affects the development of literacy and language, characterized by difficulties with phonological processing, rapid naming, working memory, processing speed, and the automatic development of skills that may not match up to an individual's other cognitive abilities." ${ }^{21}$ The dyslexic population is heterogeneous with three clinical types of dyslexia:

- Surface: difficulty in recognizing the visual form of written words, especially if they are irregular.

- Phonological: a specific inability for handling speech sounds and the grapheme-phoneme conversion.

- Mixed: combining the two types of anomalies and which is the most frequent. ${ }^{22}$

A disorder of postural regulation may be responsible for the clinical presentation known as the Postural Deficiency Syndrome (PDS). Certain authors attribute it to a proprioceptive dysfunction. ${ }^{23}$ In these patients with nonspecific pain and no apparent lesion, we note the presence of a low-level vertical heterophoria $(\mathrm{VH})$ characterized by its lability. This term expresses the fact that certain specific actions on postural sensors distant from the eye (mouth, foot, proprioception of the paravertebral muscles or of the muscles of mastication) may radically alter the $\mathrm{VH} .{ }^{24}$ Their origin is unknown. Their disappearance after specific treatment is accompanied by a significant decrease in pain symptoms and an improvement in the results measured on a postural platform. ${ }^{25}$

In addition to the results determined on the postural platform, all dyslexics appear to present clinical signs of PDS. ${ }^{26}$ Its treatment improves reading speed and some decoding capabilities in dyslexics. ${ }^{27}$ Analysis of postural data, recorded in a group of dyslexic children, also shows a positive correlation between postural improvement and the ability to focus attention. ${ }^{28}$ Poor integration of proprioceptive information plays a role in the postural dysfunction of these children. ${ }^{29}$ It is possible to counter this dysfunction by changing the visual information through a specific action on the oculomotor system. ${ }^{29}$

Given the presence of postural disorders in dyslexics and the presence of VH described in the PDS, it seems logical to investigate whether dyslexics have labile VH. This research will be done keeping in mind that $\mathrm{VH}$ is a common phenomenon present in $>20 \%$ of the general population with no specific clinical signs. ${ }^{30}$

\section{Methods \\ Participants}

Sixty-four children were recruited from a pediatric ophthalmological consultation. They were tested within the guidelines of the Declaration of Helsinki, with the informed consent of their parents. They had a visual acuity of 20/20 in both eyes. The study was an observational clinical study with no therapeutic intervention and therefore did not require approval from the Ethics Committee.

The inclusion criteria for the dyslexics were a childhood history of dyslexia with a documented diagnosis, a past history of speech therapy, and a score of at least 24 months of literacy retardation on the Written Word Identification Test (WWIT/TIME 3 test). ${ }^{31}$ This test, spread over eight grade levels in 1,806 children, identifies the decoding skills and the comprehension and spelling of 40 words for children aged $7-15$ years using eight subtests. The result is given in months of deviation from a database corresponding to children of the same age. For dyslexic children only, using the Odedys Battery helped classify the characteristics of dyslexia by assessing the reading of regular words, irregular words, pseudowords, and phonological capabilities. ${ }^{32}$ 
Children with the following visual features were excluded: strabismus with or without surgery, orthoptic rehabilitation in progress, reeducated amblyopia, refractive error $> \pm 0.50$ diopters (D) based on evaluation with cyclopentolate, stereopsis always better than 100 arcsec, and organic abnormalities of the anterior or posterior segments. Other, more general, exclusion criteria were delayed or abnormal psychomotor development, IQ $<85$, a history of neurological, psychiatric, or genetic disease, orthodontic treatment in progress, and children under psychotropic treatment, especially drugs from the phenylethylamine group or antiepileptics.

A total of 42 dyslexic children ( 22 males and 20 females) aged $118.5 \pm 12.9$ months participated in the study and were compared with a control group of 22 nondyslexic children (eleven males and eleven females) aged $112 \pm 9.8$ months. The average age, $99.4 \pm 11.9$ months, of the dyslexic reading group on the WWIT/TIME 3 test could be established in 28 of the dyslexics. The other 14 had significant delays far below the minimum values for their age. The average value for normal readers is $129.1 \pm 21.5$ months $(F(38.56), P<0.0001)$ with a homogeneous distribution across all grade levels and sexes. Of the 40 items, the mean level of identification of written words is $19.3 \pm 6.4$ and $31.3 \pm 4.4(F(62.64), P<0.0001)$. On Odedys tests, interpretable in all dyslexics, of 20 items shown to dyslexics, reading is correct for $15.6 \pm 3.6$ regular words (mean time $=50.3 \pm 24.4$ seconds), 8.8 \pm 5.3 irregular words (mean time $=59.4 \pm 35.5$ seconds), and $13 \pm 3.6$ pseudowords (mean time $=52.7 \pm 26.4$ seconds). Of the ten items for each of the two meta-phonological tests, the average score was $7.5 \pm 2.5$ for the test to delete the initial phoneme and $7.4 \pm 2.0$ for the acronyms test. Within the 42 dyslexics, 14 had surface dyslexia, four had pure phonological dyslexia, and 24 had mixed dyslexia.

\section{Experimental procedure}

\section{Visual assessment}

It consists of a visual acuity measurement with a cycloplegic refraction. The assessment of stereoscopic vision (Test of Netherlands Organisation for Applied Scientific Research [TNO] test) is completed by a standard and alternating cover test and identification of the dominant eye using the hole method (the patient holds a sheet with a hole in its center at arm's length and must aim for a light through the hole while rapidly approaching one of the two eyes).

\section{Labile VH measurement using the Maddox postural test}

The adjective postural attached to Maddox test is the protocol described below in order to distinguish it from the classic
Maddox test used in the normal strabismus practice. It is performed with a red Maddox rod, consisting of 17 biconvex cylinders that give enough convergence to transform the image of a point of white light into a red line perpendicular to the cylinder axis. The patient then sees two dissociated images from the light source: a red horizontal line through the Maddox rod and a colorless light point in direct vision. The light is placed $4 \mathrm{~m}$ from the subject at eye level. It must be emphasized that it must be very small so that the red line caused by the Maddox screen is as thin as possible (the surface of commonly used fixation points should be reduced to obtain a size of $1.2 \mathrm{~mm}$ ). The streaks are positioned parallel to the vertical axis of the eye (and must accompany the eye when the subject tilts the head on the shoulder). The test is performed for each of the two eyes starting with either the right or left and leaving a time of 1 second between each eye so as to provide a moment of binocular fusion. The child must reply, without changing the position of the tongue, by directing the thumb horizontally, up, or down indicating that the red line has been seen, respectively, in the exact center, above, or below the light. A clear illustration will explain what is expected of them by specifically emphasizing the difference between an oblique line and a line located above or below (Figure 1). For the clinician, this test is the simplest and the most effective way to measure the low-amplitude $\mathrm{VH}$, and its effectiveness is comparable to methods using more invasive measures. ${ }^{33}$

The test was performed using seven precise conditions to successively stimulate different postural sensors. The oblique muscles are then solicited by positioning the head on each shoulder (Bielchowsky Head Tilt test [BHTT]). These maneuvers are used to uncover a possible unilateral or bilateral dysfunction of the oblique muscles whose torsional action is closely linked to postural reflexes. ${ }^{34-36}$ The seven conditions always follow the same order.

- Condition 1: patient sitting in a spontaneous and natural position, without plantar support. The position of the tested eye is noted as vertical orthophoria (VO),

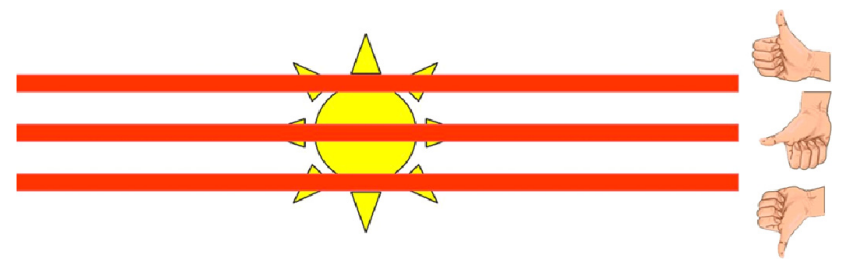

Figure I How to indicate the position of the line without changing the position of the tongue.

Notes: Thumb up represents red line above the light, horizontal thumb represents red line strictly in the center of the light, and thumb downward represents red line under the light. 
hyperphoria, or hypophoria. Measuring the potential $\mathrm{VH}$ is performed using vertical prisms from $0.25 \mathrm{D}$ to $1.00 \mathrm{D}$ in increments of $0.25 \mathrm{D}$. If no prism perfectly corrects the $\mathrm{VH}$, the value of the last prism that leaves the red line in its original position and the first prism that passes the line above or below (or vice versa) the light is recorded (for example, $\mathrm{VH}$ between $0.25 \mathrm{D}$ and $0.50 \mathrm{D}$ when the red line was initially under the light, remained when interposing a $0.25 \mathrm{D}$ prism, and passed over the light with a $0.50 \mathrm{D}$ prism).

- Condition 2: sitting straight up without plantar support. This position changes the spinal proprioception.

- Condition 3: condition 2 but with the tip of the tongue firmly touching the central retro-incisor papillae. This contact stimulates recovery of a corporal postural reflex related to contact with the lingual and palatine mucosa. ${ }^{37}$

- Condition 4: condition 2 with lips tightly serrated. The stimulation of the facial nerve during this movement has an antagonistic action on the trigeminal nerve (Bratlawski reflex), of which the upper branch carries ocular proprioceptive information. ${ }^{38}$

- Condition 5: condition 2 with the tip of the tongue planted against the lower incisors to mechanically stimulate periodontal ligaments that may be involved in one aspect of the feeling of body ownership. ${ }^{39}$

- Condition 6: standing in a natural position to add the information from the plantar sole with the mouth also in a natural position.

- Condition 7: condition 6 with a foam insole between the foot and the ground to decrease proprioceptive plantar information. ${ }^{40}$

At the end of this first part of the test, an index of lability is created. It corresponds to the number of times, as a result of the stimulation of one of the sensors, the type of VH has changed when compared to the previous stimulation. Sensors whose stimulation eventually leads to VO of both eyes are also listed in Table 1.

The postural Maddox ends by seeking the effect on $\mathrm{VH}$ or VO of a bilateral BHTT with the subject in condition 1. If the red line ascends, superior oblique hypertonia is suspected. Hypertonia of the inferior oblique will distance the red line downward from the light. Looking for a variation in height in adduction is not done since the results are not reliable due to the minimal values of $\mathrm{VH}$ when measured in the primary position.

\section{Measuring torsion (cyclotropia)}

The presence of subjective torsion is determined using the double Maddox rod test performed with a Maddox white glass and a Maddox red glass, the latter always being placed by convention before the left eye. The two glasses are mounted in a trial frame with a level to ensure that the measurement takes place with the head in a strictly vertical position. ${ }^{41}$ A vertical prism of $6 \mathrm{D}$ placed in front of the right eye limits the possibilities for fusion. The patient is then asked to report when the white and red lines appear to be parallel. The difference in angle between the two lines, visible on the trial frame graduations, indicates how much torsion is present. A photograph of both eyes is taken using a non-mydriatic fundus camera, keeping the patient's head strictly vertical (use of back and forth motion from one eye to the other to ensure that the sight is always aimed at the center of the pupil). The photos are used to measure the angle of the line joining the fovea and the center of the optic disc with the horizontal line through this point (Solidworks ${ }^{\mathrm{TM}}$ program, Dassault Systèmes, Paris, France). ${ }^{42}$ The difference in torsion between the two eyes is noted.

\section{Correcting VH using prisms}

If the patient is not constantly in VO during the successive stimulations of the Maddox postural test, he (or she) is put

Table I Index of lability

\begin{tabular}{|c|c|c|c|c|c|c|c|c|c|c|c|c|c|}
\hline \multirow[t]{2}{*}{ Conditions } & \multicolumn{2}{|c|}{$\begin{array}{l}\text { (I) Sitting } \\
\text { in natural } \\
\text { position }\end{array}$} & \multicolumn{2}{|c|}{$\begin{array}{l}\text { (2) Sitting } \\
\text { straight up } \\
\text { without } \\
\text { plantar } \\
\text { support }\end{array}$} & $\begin{array}{l}\text { (3) Tip of the } \\
\text { tongue firmly } \\
\text { touching the } \\
\text { central retro- } \\
\text { incisor papillae }\end{array}$ & $\begin{array}{l}\text { (4) Lips } \\
\text { tightly } \\
\text { serrated }\end{array}$ & $\begin{array}{l}\text { (5) Tip of } \\
\text { the tongue } \\
\text { planted } \\
\text { against the } \\
\text { lower incisors }\end{array}$ & \multicolumn{2}{|c|}{$\begin{array}{l}\text { (6) Standing } \\
\text { in a natural } \\
\text { position }\end{array}$} & \multicolumn{4}{|c|}{$\begin{array}{l}\text { (7) Standing } \\
\text { in a natural } \\
\text { position } \\
\text { with a foam } \\
\text { insole }\end{array}$} \\
\hline & h & $\mathbf{H}$ & 0 & $\mathbf{H}$ & $\mathbf{H}$ & h H & $\mathbf{H}$ & 0 & $\mathbf{H}$ & 0 & 0 & $\begin{array}{l}\text { No of the } \\
\text { condition } \\
\text { giving VO }\end{array}$ & $\begin{array}{l}\text { Index } \\
\text { of lability }\end{array}$ \\
\hline $\begin{array}{l}\text { Points for } \\
\text { lability index }\end{array}$ & 0 & & I & & 1 & 0 & 1 & 0 & & I & & 1 & 4 \\
\hline
\end{tabular}

Note: Each time that the type of $\mathrm{VH}$ changes as a result of the stimulation of one sensor (when compared to the previous stimulation) gives I point. Abbreviations: $\mathrm{VH}$, vertical heterophoria; $\mathrm{O}$, line in the middle of the light; $\mathrm{h}$, line over the light; $\mathrm{H}$, line under the light; $\mathrm{VO}$, vertical orthophoria. 
back in condition 1 for a prism test. The choice of prism is made according to the rules established as a function of visual characteristics (presence of pseudo-directional scotoma detected with the synoptophore) and evaluation of the tonicity of postural muscles (cervical and hip rotator muscles). ${ }^{43}$ This choice is justified in that $\mathrm{VH}$ is not considered to be a purely ocular dysfunction but a result of information from within the entire postural system. ${ }^{24}$ The presence of hyper or hypophoria of an eye does not determine the choice of prisms. The important thing is to attain VO associated with a symmetric tonicity of the corporeal muscles controlling posture.

The examination begins with a study of cephalic rotation and extension. If the rotation is limited on the side where the extension is shorter, we propose a trial with prisms having a base at $125^{\circ}$ in front of the right eye and at $55^{\circ}$ in front of the left eye if lower oblique hypertonia is present. ${ }^{23}$ In the presence of superior oblique hypertonia, we use prisms with a base at $235^{\circ}$ before the right eye and at $305^{\circ}$ before the left eye. The power will be $2 \mathrm{D}$ for one eye and $3 \mathrm{D}$ for the other eye, the stronger prism placed on the side where the head rotation is decreased.

If head rotation is limited on one side and extension is shorter on the opposite side, a search for directional pseudoscotomas is mandatory. ${ }^{23}$ These are zones of total or relative losses (decreased contrast) in visual perception that appear during bilateral versions on the synoptophore examination. ${ }^{44}$ The examination should be carried out with large patterns (The Clement Clarke G3-G4 cage patterns and lion image). The lighting of the test patterns must be absolutely minimal (no 1). The patient is asked to look at the images of the two patterns and report if all or part of an image fades out as "if an eraser was used to remove some color from the images". The test is done with the right and left visual axis at $20^{\circ}, 30^{\circ}$, and eventually $40^{\circ}$. The angle at which the scotomas appear is logged.

- If the pseudo-scotomas appear at the same version angle, the prisms are tested as described above, the side of the strongest prism being selected from the results of a test on the hip rotators. This osteopathic test assesses the stretch resistance of the external rotator muscle groups of the thighs by imparting a passive internal rotation to the feet. The subject is placed supine on an examination table with gaze in the primary position and arms extended. The practitioner simultaneously and slowly imposes internal rotation of the right and left lower limbs. A symmetrical rotation indicates that the prism normalizes postural tone.
- If the pseudo-scotomas appear at version angle $X$ on one side and at angle $X+10^{\circ}$ on the other, an oblique prism will be tested unilaterally on the eye measuring $X+10^{\circ}$.

- If the pseudo-scotomas appear at version angle $X$ on one side and the angle $X+20^{\circ}$ on the other, a horizontal prism of $2 \mathrm{D}$ or $3 \mathrm{D}$ will be tested unilaterally on the eye measuring $X+20^{\circ}$.

If the $\mathrm{VH}$ is not reduced during the test, the axis of the prism is changed by rotating in $5^{\circ}$ increments, always starting with the strongest prism, just until VO is obtained. Conditions 2-7 are then retested with the prisms in place to verify the stability of the resulting effect and determine the new index of lability. The sequence is the same for the BHTT, right, left, and for the double Maddox rod test (but without interposing a vertical prism to separate the two white and red lines, the subject indicating that the two lines merge in the absence of torsion). Specifically for this study, we also attempted to correct any $\mathrm{VH}$ with a vertical prismatic correction in order to compare its effect to the oblique corrections.

Table 1 reveals whether the prismatic correction results in a permanent $\mathrm{VO}$, whether one or more sensors are required in addition to prisms to obtain a perfect $\mathrm{VO}$, or if some sensors disrupt the previously obtained VO.

\section{Horizontal heterophorias and convergence}

They are uncovered for distance vision using the same equipment with the streaks of the Maddox rod placed horizontally. The convergence is measured for near vision in centimeters using the Mawas ruler; the divergence was not measured.

\section{Statistical analysis}

Data were described using mean \pm standard deviation for quantitative variables, frequency, and percentage for ordinals and qualitative variables. Comparisons of means were conducted with one-way ANOVA, and comparisons of percentages with $\chi^{2}$ or their nonparametric equivalent like Wilcoxon test or Fisher's exact test if required. Correlation between quantitative variables was measured using the Pearson's coefficient test. $\alpha$ was equal to 0.05 . Double entry of data was made on Capture system and analyzed with SAS Version 9.3 by the Department of Biostatistics of the Medical Evaluation Chair ESC, Dijon.

\section{Results \\ Vertical heterophoria}

There is no difference between the two groups with respect to ocular dominance $\left(\chi^{2}=2.01, P=0.15\right)$. No child had visible eye 
movement on the alternating cover test. Sitting completely relaxed without pedal support, only $4.8 \%$ of dyslexics have normal VH if we adhere to the physiological value of $0.25 \mathrm{D}$ proposed by Van Rijn. ${ }^{45}$ The $\mathrm{VH}$ of the remaining $95.2 \%$ is always $<1 \mathrm{D}$. Despite this very low value, only two dyslexics have a VH that can be precisely corrected using vertical prisms in increments of $0.25 \mathrm{D}$. All others are either undercorrected or overcorrected when tested with this type of prism. Among the normal readers, 68.2\% have a normal vertical phoria. The difference between the two groups is extremely significant $(P<0.0001)$.

\section{Torsion and the BHTT}

Examination with the double Maddox rod reveals significant torsion in dyslexics. It is on average $1.9^{\circ} \pm 0.9^{\circ}$ in comparison to $0.1^{\circ} \pm 0.4^{\circ}$ in the normal readers group, with only one actually having a detectable torsion $(F(72.91), P<0.0001)$. When it presents, it is always an excyclotorsion of the left eye. The five dyslexic children who will have bilateral superior oblique hypertonia at the BHTT did not present, with the exception of one case, any detectable intorsion or extorsion.

There is a difference, on retinophotography, in torsion between the two groups. Contrary to what is observed for the right eye ( $F(2.53), P=0.12)$, the excyclotorsion of the left eye in the dyslexic group was significantly greater than that of the normal reader group $(F(4.90), P=0.03)$. The double Maddox rod and the retinal photographic results had no statistically significant link ( $R=0.17, P=0.42$ ). Retinal photographs did not reveal incyclotorsion in either group.

During the BHTT, the effect of tilting toward a shoulder is significantly different for the two groups $\left(\chi^{2}=36.62\right.$, $P<0.0001)$. In normal readers, it was in fact positive for only $27.3 \%$ of the 22 children, while the vertical deviation is changed in all, except one, of the dyslexic children (97.6\%). In the dyslexic group, the deviation appears during tilting toward the two shoulders in 27 of the 42 children (64.3\%). Hypertonia of the two inferior oblique muscles is the cause in $75 \%$ of cases ( 15 cases), and hypertonia of the two superior oblique muscles is the cause in the remaining $25 \%$ (five cases). When hypertonia is different for each of the two eyes (seven cases), the patient most often (six out of seven cases) presents the combination of left superior oblique and right inferior oblique hypertonia. If, during the BHTT, deviation appears for only one eye $(33.3 \%)$, it is most often the left eye $(64.3 \%)$. In the group of normal readers, if a deviation appears, it is the left inferior oblique muscle that is hypertonic ( $85 \%$ of cases with deviation). A unilateral superior oblique hypertonia was observed in only one case.

\section{Lability}

If we look at the lability level together with postural sensors, we find that lability is always present for dyslexics and absent for $81.9 \%$ of normal readers $(P<0.0001)$. For the $18.1 \%$ of normal readers with lability, the level is low, always $<3$. It meets or exceeds this value in $73.8 \%$ of dyslexics rising to $5(26.2 \%)$ and $6(11.9 \%)$. The difference manifests itself when eliciting the Bratlawski reflex $(P<0.05)$, with stimulation of the lower dental ligaments $(P<0.01)$ and with stimulation of the isolated plantar sensor $(P<0.01)$ or with the foam insole $(P<0.05)$.

The level of lability is independent of the age of dyslexics ( $F(0.70), P=0.62)$ or sex $(P=0.44)$. It is not related to ocular dominance $(P=0.45)$. In the dyslexic group, there was no significant relationship between torsion and lability $(F(0.405)$, $P=0.84)$ whether measuring with the double Maddox rod or with fundus photography $(F(0601), P=0.70)$. This lack of a relationship stood for examinations of either the left or the right eye $(P=0.50)$. Lability is not dependent on the initial position of the eye behind the Maddox $\operatorname{rod}(P=0.47)$, the value of $\mathrm{VH}(P=0.36)$, or the power of the prism able to correct it when under condition 1 of the test. It also does not depend on the results of the BHTT except if there is left lower oblique hyperactivity $(P=0.01)$.

\section{Heterophorias and horizontal convergence}

In contrast to the normal readers group, the presence of a low-level ( $2 \pm 1.2 \mathrm{D})$ esophoria characterizes children (81\%) of the dyslexic group when fixating for distance vision $\left(\chi^{2}=30.2, P<0.0001\right)$. It improves with oblique prisms $(P=0.04)$, but the change is moderate, since only half of the initially esophoric dyslexics become orthophoric or slightly exophoric. The esophoria on distance fixation is unexpectedly partnered with a very reduced punctum proximum of convergence $(11.5 \pm 2.8 \mathrm{~cm})$. It improves significantly with the use of prisms but still remains below that of normal readers $(9.7 \pm 1.8 \mathrm{~cm}$ vs $7.1 \pm 2.2 \mathrm{~cm}, P<0.0001)$.

\section{Prism effect on $\mathrm{VH}$}

In the group of 42 dyslexics, we were able to suppress the $\mathrm{VH}$ in 39 children (93\%) when they were in the relaxed sitting position without plantar support. For 31 dyslexics, normalization was achieved using bilateral prisms only to relax the inferior oblique (26 cases) or the superior oblique (five cases). When hypertonia of a superior oblique and an inferior oblique is present, it is the effect on the feet convergence test that indicates which oblique muscles to relax. 
The prisms for the left and right eyes are always of unequal power (2D and 3D). If prisms with their base in the superiorlateral position are used to release the lower obliques, the axes of the prism base are $125^{\circ} \pm 10^{\circ}$ for the right eye and $30^{\circ} \pm 10^{\circ}$ for the left. When an action on the upper obliques is sought, the axes are $240^{\circ} \pm 10^{\circ}$ for the right eye and $320^{\circ} \pm 10^{\circ}$ for the left. It was possible in just two cases to suppress the VH interchangeably with either bilateral oblique prisms or a unilateral vertical prism. The latter must always be placed before the dominant eye. In eight cases, the stimulation of a postural sensor in addition to the oblique prisms was required to obtain VO.

There was no significant mathematical relationship between the value of the $\mathrm{VH}$ and the prismatic combination used $(P=0.49)$. The initial rate of lability does not affect the possibility of prismatic correction, either oblique $(P=0.77)$ or vertical $(P=0.19)$, even when we have to stimulate a sensor to obtain $\mathrm{VO}(P=0.22)$.

In the normal readers group, suppression is achieved in a significantly different manner $(P=0.002)$. In seven patients with $\mathrm{VH}$, five cases responded to treatment with a vertical prism and the remaining two cases corrected with oblique prisms. Complementary stimulation of a postural sensor was never required to obtain $\mathrm{VO}$ in this group.

\section{VO lability corrected by prisms}

After prism placement, the average level of lability of the dyslexics decreases significantly from 3.75 to 0.3 . Lability disappeared completely in 33 dyslexics. It was still present in nine dyslexics with a value of 1 for five of them and an average value of 3 for the others with the stomatognathic sensor then usually at fault. During the BHTT, unilateral VH reappears in seven dyslexics and three dyslexics have a phoria on bilateral tilt. Lability that sometimes persists in the dyslexic group is independent of the initial lability $(P=0.15)$.

In the normal readers group, when obtaining $\mathrm{VO}$ required the use of prisms, there was no corporeal sensor-induced lability. Only two cases retained lability on only one shoulder during BHTT.

If we analyze each of the postural sensors, the lability of dyslexics equipped with prisms becomes identical to that originally found in the normal readers group ( $P$ between 0.47 and 1 for different sensors). This is also the case for changes occurring during the BHTT $(P=0.38)$.

\section{Prism effect on torsion}

Torsion (using the double Maddox rod test) is corrected by prisms in $81 \%$ of dyslexic children with the level becoming similar to that found in normal readers $(P<0.0001)$. Only eight dyslexic children have a residual torsion of $2.1^{\circ} \pm 0.2^{\circ}$. VO could not be achieved in half of these children. Due to technical constraints, retinal photographic assessment of torsion with prisms is not feasible.

\section{$\mathrm{VH}$ and reading skills}

There is no significant relationship between the value of the $\mathrm{VH}$ and the delay in reading capacity measured in months ( $P=0.24)$, the type of dyslexia $(P=0.24)$, and the various Odedys tests ( $P$-value is always $>0.05)$. Whether measured with the double Maddox rod and with retinal photography, the torsion angle is unrelated to the reading level (Pearson coefficient, respectively, 0.11 and -0.10$)$. It is the same for the type of dyslexia $(F(1.195), P=0.31$ and $F(0.792)$, $P=0.46)$, the reading level, and the various Odedys tests ( $R$ is between -0.23 and 0.10 and $P$ is always $>0.05$ for these three elements).

Whether appearing upon stimulation of postural sensors or during the BHTT, lability is not correlated with the type of dyslexia $(P=0.17)$, reading delay $(P=0.95)$, the type of errors on WWIT/TIME 3 test, or the various Odedys tests ( $P$ is always $>0.05)$.

\section{Discussion}

\section{Labile VH in the dyslexic}

Very little research has been done in dyslexic children on vertical movements and deviations or on cyclophorias and torsions. Only vertical phorias visible on the cover test with deviations $>3 \mathrm{D}$ have been evaluated. ${ }^{46}$ They are no different from those found in nondyslexic children. The unique study characterizing the vertical eye movements of the dyslexic fixating on a moving target showed a longer lag time, with reduced gain and speed, as well as a higher rate of anticipatory and express saccades. ${ }^{47}$ As in the normal reader, saccades are slower and hypometric when looking up and faster and hypermetric when looking down. In the dyslexic, however, lag time is more important when looking down, suggesting dysfunction of muscles having a vertical action.

Our work represents the first study of small $\mathrm{VH}$ in the dyslexic. When the highly specific requirements of the examination, as described, have been followed, all dyslexics present a very particular $\mathrm{VH}$, which differentiates them clearly from normal readers $(P<0.0001)$ :

- It is constant and independent of the type of dyslexia.

- It is mild, usually between $0.25 \mathrm{D}$ and $0.75 \mathrm{D}$, and not detected on a simple cover test. However, it is relevant 
if we accept the physiological value of $0.10 \mathrm{D}-0.16 \mathrm{D}$ proposed by Van Rijn et al. ${ }^{45}$ Despite its low level, the patient is not able to voluntarily compensate for it. This is almost always unchanged with the use of vertical prisms of very low power.

- It is labile. This lability appears during specific stimulation of sensory receptors known to be involved in postural regulation. The change is qualitative (modifying a VH or VO). Lability is also expressed quantitatively during the BHTT. The lability index is high.

- It seems to represent the vertical translation of an imbalance in tonicity of the oblique muscles. Indeed, it is associated with subjective and objective torsions and often changes during the BHTT. In addition, the prisms used for correction act primarily on the oblique muscles, and the rare possibility of correction by a vertical prism fails to suppress the lability. BHTT shows that it is most often due to hypertonia of the lower oblique muscles and also rarely to a blocking in the superior oblique muscles, which evokes the picture of a minimal Brown syndrome.

- The use of bilateral oblique prisms, selected on the basis of the ophthalmological data and also from the study of postural tone, corrects VH, lability, and torsion in the vast majority of cases. The prismatic correction is only effective when relaxing the hypertonic muscles bilaterally and asymmetrically, with axes that rarely correspond to the theoretical axis of the muscles' insertions. This suggests that orbital anatomical factors may be involved in the pathogenesis. In some cases, correction is impossible. In other cases, it can be attained through stimulation of the superior oblique muscles during head tilting on the shoulder or with complementary stimulation of a postural sensor.

\section{Torsion in the dyslexic}

With the exception of one child, the double Maddox rod test consistently reveals torsion in the dyslexic group. It is of low amplitude but separates significantly the dyslexic group from the normal readers group $(P<0.0001)$. Left-side excyclotorsion is the most common result on the double Maddox rod test, whereas fundus photography shows a significant number of right-side excyclotorsions. This could be related to the fact that at the moment the photo is taken, the measurement corresponds more to a phoria than to torsion since the image formed by the two eyes is completely dissociated. The difference in values, sometimes considerable, from those found with the double Maddox rod also supports this hypothesis.

Torsion measured with the double Maddox rod almost always disappears with the placement of oblique prisms and exceptionally with the use of a vertical prism. This seems to confirm the link between torsion and $\mathrm{VH}$ and the highly probable role of the vertical component of the oblique muscles in the genesis of the VH. It is certainly important that the torsion is corrected to optimize the quality of reading because torsional eye alignment is essential in order to obtain stereoscopic perception. ${ }^{48}$ The effect of a tonic imbalance in the oblique muscles may be even more important in the reading position because torsional deviations are exaggerated in downward gaze when superior oblique muscle function is altered. ${ }^{48}$

In the scientific literature, there is much less research on cyclovergences that could offset torsion than on horizontal convergence. Physiologically, cyclovergence is zero in the primary gaze position. It is, on the other hand, highly solicited for the normal reading position since the eyes have a tendency toward extorsion in downgaze. ${ }^{49}$ Physiologically, when a disparity appears, adaptation by cyclovergence is slower than the adaptation by vertical convergence. It is less effective for excyclodisparities than for incyclodisparities. ${ }^{50}$ This adaptation is also dependent on horizontal convergence. It is reduced in our group of dyslexics, confirming results previously shown in other studies. ${ }^{51}$ In healthy subjects, cyclovergence is however, very effective because when it occurs, the result is an almost perfect symmetry between both eyes, the difference being only $0.07^{\circ} .52$

The visual feedback from a retinal image does not intervene in its quality. ${ }^{49}$ For some authors, this is proof that the participation of the oblique muscles in the maintenance of high-quality fusion depends more on postural reflexes than on information from retinal images. ${ }^{34}$ This reinforces the idea of a relationship between torsion, $\mathrm{VH}$, and dysfunctional postural control in the dyslexic.

\section{The link between $\mathrm{VH}$ and torsion in the dyslexic}

The presence of torsion does not mean that the vertical rectus muscles are not at all involved in the VH. Torsion and vertical fusion are indeed closely linked, in part because the vertical rectus muscles and the oblique muscles have a common control center in the nuclei of the diencephalon. This is certainly why the experimental creation of a vertical deviation by the interposition of a vertical prism of $1.5 \mathrm{D}$ always provokes concomitant torsion associated with a compensatory vertical 
movement. ${ }^{53}$ The detected vertical phoria could therefore also correspond to a global dysfunction of muscles with a vertical action with the relative responsibility of the rectus and oblique muscles differing according to the position of gaze. The movements of vertical vergence and cyclovergence, and also horizontal convergence, are indeed very intricate, especially in tertiary gaze positions that are highly solicited when reading on a horizontal table. This position solicits convergence and downgaze with a different depth for each eye when scanning the text. Gaze position and horizontal convergence are thus constantly variable. All vertically acting muscles are then solicited. If adduction is provided by the medial recti with help from the inferior recti, depression is obtained by a synergy between the inferior recti and the superior oblique muscles. The rotation caused by the inferior recti and by the superior oblique muscles must cancel each other out. It would have been interesting to calculate $\mathrm{VH}$ and cyclophorias in near vision and in downgaze. This was not possible with the proposed technique because in near vision, diffraction through the Maddox screen greatly enlarges the red line and prevents precise evaluation of the displacement with the light. A similar constraint has prevented accurate measurement of horizontal phoria variations in near vision.

The BHTT, used to determine the choice of orientation of the oblique prisms, is very informative concerning the relationship between $\mathrm{VH}$ and torsion. While horizontal vergence is the only one under voluntary control, there are involuntary couplings between the conjugate position of the eyes, the horizontal vergence, and head position when guiding vertical vergence and cyclovergence. ${ }^{51}$ Vertical ocular equilibrium therefore also depends on the position of the head. Therein lies the possibility of a link with the PDS that is characterized by a slight rotation and discrete lateral tilting of the head. ${ }^{26}$ In this position, information originating from the inner ear provokes opposing ocular movements with excyclotorsion on the side opposite to the head tilting and incyclotorsion of the eye closest to the shoulder. This reflex reaction is largely due to action of the inferior oblique muscles that have the capacity to compensate for $10 \%$ of cephalic inclination. The ipsilateral eye, through the action of the superior oblique, has a tendency to depress, while the other eye has a tendency to elevate via the action of the inferior oblique. However, under normal physiological conditions, the difference is quasi-null for distance vision since the compensation is stable in all gaze positions. ${ }^{54}$ This compensation is more fragile for near vision making oculomotor equilibrium more difficult to maintain while reading. ${ }^{55,56}$ In the dyslexic group, the difference appears quasi-systematically on both shoulders in the form of unilateral or bilateral oblique muscle hyperactivity. In the normal readers group, this effect is found in only $18 \%$ of cases. The dyslexic's oculomotor reaction on the BHTT establishes an additional link between $\mathrm{VH}$ and the presence of a globally dysfunctional proprioception in the dyslexic patient. Cervical proprioception, when involved in the compensatory oculomotor reaction, is in effect closely linked to plantar as well as paravertebral muscle proprioceptive information. ${ }^{57,58}$

\section{Significance of $\mathrm{VH}$ in the dyslexic}

The constant presence of a very low-level labile VH associated with torsion raises the question of its significance with respect to reading difficulties in the dyslexic. Indeed, if there is a clear relationship between the presence of a labile $\mathrm{VH}$ and that of dyslexia, our study shows that its characteristics are not correlated to the different tests assessing reading delay.

Lability is a central feature of $\mathrm{VH}$ in the dyslexic and is similar to that which was found during the PDS found in patients suffering from chronic pain. ${ }^{24,59}$ Its addition to the clinical presence of PDS found in all dyslexics establishes a relationship between dyslexia, proprioception, and postural control. ${ }^{26}$ This relationship helps to better understand the observed improvement in some aspects of reading in dyslexics when postural control is improved. ${ }^{27,60}$ Improved attention in the dyslexic, released from a nonautomated constraint on postural regulation, may play a role. ${ }^{28}$

Lability establishes a link with the cerebellum in which anatomical particularities are found in dyslexics. ${ }^{61}$ Functionally, the cerebellum is part of the neural network of reading and some cerebellar lesions cause difficulties in the decoding of written language. ${ }^{62}$ For oculomotor function, the relationship between $\mathrm{VH}$ and the cerebellum could be fairly straightforward. Indeed, cerebellar disorders are often associated with a poor capacity to adapt to vertical phoria. We can then find a horizontal-eye-position-dependent vertical skew deviation that appears identical to what is obtained with unilateral ocular occlusion (the occluded eye starts elevation during abduction). ${ }^{63}$ Furthermore, the cerebellum is strongly involved in postural control by integrating visual (magnocellular pathway), vestibular, somatosensory (such as skin receptors), and proprioceptive (muscular and articular receptors) information. ${ }^{64}$

\section{$\mathrm{VH}$ and postural regulation}

In the dyslexic, postural regulation has been the subject of several studies with somewhat contradictory findings. The effect of postural disorder on dyslexia could therefore be interpreted through a diverse genetic mechanism with no 
real causal relationship. ${ }^{65,66}$ However, when tested on a force platform, dyslexics show greater instability with eyes either opened or closed. ${ }^{17,18}$ Disturbances concern both spatial and temporal constants. ${ }^{67}$ The ability to focus attention, impaired in the dyslexic, could participate in this imbalance. ${ }^{29,68}$ It is however, less apparent in older dyslexics. ${ }^{69}$ Conversely, a lack of automation of postural regulation may impair cognitive performance for tasks requiring attention. ${ }^{70}$ The interdependency between vision, eye movement, and the cerebellum is often cited to explain postural disorders in the dyslexic. The imbalance is indeed very dependent on visual information and may vary depending on whether the information originates centrally or peripherally, whether the eyes are in motion or stationary, and also on imposed (voluntary) eye movements. ${ }^{19,68}$ This dependence on the manipulation of visual information seems to be independent of any association with a cognitive task but varies as a function of ocular vergence. ${ }^{71}$ The use of high-power horizontal prisms or lenses disrupting accommodation has a negative effect. ${ }^{72}$ We note however that postural control can be improved by the use of very low-power oblique prisms (2D-3D) correcting $\mathrm{VH}^{28,29}$ The presence of $\mathrm{VH}$ also alters postural balance in young healthy adults. Those presenting with a low-level $\mathrm{VH}$ (distance fixation) are less stable than those in VO, and VH correction improves postural stability. ${ }^{73}$ Conversely, experimental placement of a 2D prism, base inferior, before the nondominant eye causes an increase of anterior-posterior body oscillations with fixation at any distance. Placed in front of the dominant eye, the effect is reversed but only for fixation at a distance of $2 \mathrm{~m} .{ }^{74}$ The vertical convergence induced by the presence of the prism confirms that the reaction is modulated by ocular dominance. ${ }^{78}$ The role of retinal dominance could be influenced by ocular proprioceptive information. ${ }^{10}$ In accordance with what we suggest for the dyslexic, other authors propose that low-level VH is not a reflection of an ocular pathology but of a disruption in the somatosensory and proprioceptive control pathways involved in postural regulation.

\section{$\mathrm{VH}$ and proprioception in the dyslexic}

In the visual cortex, which appears to be different in the dyslexic even before learning to read, proprioceptive information is taken into account. ${ }^{76}$ Experimentally, ocular proprioception is indeed capable of modifying, functionally as well as anatomically, the microscopic structure of the visual cortex. In animals, muscle elongation causes an activity that is specific to the direction of movement. This activity disappears with the removal of proprioceptive information by anesthetic infiltration into the muscle. ${ }^{77}$ The section of the trigeminal nerves, which transport ocular proprioceptive information, disrupts the appearance of columns for orientation in the visual cortex and the establishment of ocular dominance and of a normal binocular vision. ${ }^{78}$ In cats, visual activity in area 18 varies as a function of ocular proprioception. This area has a different structure in the dyslexic even before the acquisition of reading skills. ${ }^{76}$

In the association areas, a high-quality multisensory integration is necessary for the acquisition of reading skills. While previous research has already demonstrated deficits of auditory-visual integration, the role of ocular and corporeal proprioception has not yet been investigated. ${ }^{79}$ Its participation in the spatial localization of ocular and auditory sensory information logically suggests that it could play a role in multisensory integration. The spatial-sensory coincidence is in fact an important factor in this integration. ${ }^{80,81}$

\section{The importance of $\mathrm{VH}$ in the dyslexic}

Because of the relationships that seem to exist between $\mathrm{VH}$, proprioception, and postural control, we propose that the $\mathrm{VH}$ in dyslexics can be read in the light of two ideas:

- From a purely ocular standpoint, lability causes an inconsistency in the phoric deviation during stimulation of postural sensors. This could hamper the establishment of stable oculomotor compensation strategies. The abduction caused by hypertonic oblique muscles could also be involved in the deregulation of convergence and saccades. However, our study clearly shows that there is no significant relationship between the different reading tests and the characteristics of labile VH. To clarify whether they have a minimal role per se in the disruption of the primary mechanisms of reading in the dyslexic, video-oculographic recordings of $\mathrm{VH}$ and associated ocular displacement would be necessary.

- From a more general standpoint: in the same way that it was described in the PDS, VH lability, obtained from stimulation of postural sensors, may be considered evidence of a dysfunction of the sensorimotor system that controls posture and balance. The backbone of this system is proprioception, given its role in the localization of body parts and of sensory information. ${ }^{57,82}$ In the presence of proprioceptive dysfunction, the resulting spatial-sensory incongruence could have a negative effect on the development of the high-level auditory-visual integration requisite to the acquisition of reading skills. ${ }^{80,81}$ Furthermore, 
whether it is of ocular or systemic origin, proprioception modulates visual attention. ${ }^{83,84}$ There is a deficit of this modulation in the dyslexic. ${ }^{85}$ This deficit, along with labile $\mathrm{VH}$ and torsion, appears to cross the gap between surface and phonological dyslexia.

\section{Conclusion}

Dyslexics have low-level VH associated with cyclotropia. This feature distinguishes them clearly from normal readers. The essential feature of this VH is its lability. VH does in fact vary during stimulation of the sensory receptors that intervene in postural regulation. Lability is detected by following a very specific protocol. The presence of cyclotropia, instability on the BHTT, and the type of prisms required to correct the VH suggests that VH may be the vertical effect of asymmetric hypertonia of the oblique muscles. There is no statistical relationship between the amplitude or level of lability of $\mathrm{VH}$ and the different parameters used to explore the reading skills of dyslexic children. It is the same for the amplitude of cyclotropia. The direct role of $\mathrm{VH}$ in the oculomotor disorders of dyslexia would therefore be limited. On the other hand, $\mathrm{VH}$ and cyclotropia could represent a global indicator of proprioceptive dysfunction responsible for attention disorders and high-level multisensory disturbances due to the poor spatial localization of visual and auditory information. Further work exploring multisensory perception, the relationship between proprioception and visual attention, and the effect of the correction of $\mathrm{VH}$ is needed in dyslexics.

\section{Acknowledgments}

The authors thank the parents and children for their kind participation; Philippe Rigolet (Massachussetts Institute of Technology) and Maria Pia Bucci (CNRS UMR 676) for their advice on the project.

\section{Disclosure}

The authors report no conflicts of interest in this work.

\section{References}

1. Morrison RE. Manipulation of stimulus onset delay in reading: evidence for parallel programming of saccades. J Exp Psychol Hum Percept Perform. 1984;10(5):667-682.

2. Seidenberg MS, Plaut DC, Petersen AS, McClelland JL, McRae K. Nonword pronunciation and models of word recognition. J Exp Psychol Hum Percept Perform. 1994;20(6):1177-1196.

3. Reichle ED, Warren T, McConnell K. Using E-Z reader to model the effects of higher level language processing on eye movements during reading. Psychol Bull Rev. 2009;16(1):1-21.

4. Reichle ED, Rayner K, Pollatsek A. The E-Z reader model of eye movement control in reading. Behav Brain Sci. 2003;26(4):445-476.
5. Nazir TA. Les mouvements oculaires et la lecture. In: Boucart M, Hénaff MA, Belin C, editors. Vision: aspects perceptifs et cognitifs. Marseille: Solal Edition; 1998:311-322.

6. Blythe HI, Liversedge SP, Findlay JM. The effective fusional range for words in a natural viewing situation. Vision Res. 2010;50:1559-1570.

7. Nuthmann A, Kliegl R. An examination of binocular reading fixations based on sentence corpus data. J Vis. 2009;9(5):31.1-28.

8. Zimmermann E, Lappe M. Eye position effects in oculomotor plasticity and visual localization. J Neurosci. 2011;31(20):7341-7348.

9. Ventre-Dominey J, Dominey PF, Sindou M. Extraocular proprioception is required for spatial localization in man. Neuroreport. 1996;7(9): $1531-1535$.

10. Velay JL, Roll R, Lennerstrand G, Roll JP. Eye proprioception and visual localization in humans: influence of ocular dominance and visual context. Vision Res. 1994;34(16):2169-2176.

11. Balslev D, Himmelbach M, Karnath HO, Borchers S, Bartholomaeus O. Eye proprioception used for visual localization only if conflict with the oculomotor plan. J Neurosci. 2012;32(25):8569-8573.

12. Roll JP, Bergenheim M, Ribot-Ciscar E. Proprioceptive population coding of two-dimensional limb movements in humans: II. Musclespindle feedback during "drawing-like" movements. Exp Brain Res. 2000;134(3):311-321.

13. Roll JP, Roll R. La proprioception extra-oculaire comme élément de référence posturale et de lecture spatiale des données rétiniennes [Extraoculaire proprioception as an element of postural reference and of the spatial interpretation of retinal data]. Agressologie. 1987;28:905-911.

14. Kavounoudias A, Roll R, Roll JP. The plantar sole is a 'dynamometric map' for human balance control. Neuroreport. 1998;9(14):3247-3252.

15. Mergner $T$, Rosemeier $T$. Interaction of vestibular, somatosensory and visual signals for postural control and motion perception under terrestrial and microgravity conditions - a conceptual model. Brain Res Brain Res Rev. 1998;28(1-2):118-135.

16. Brown B, Haegerstrom-Portnoy G, Herron J, Galin D, Yingling CD, Marcus M. Static postural stability is normal in dyslexic children. J Learn Disabil. 1985;18(1):31-34.

17. Pozzo T, Vernet P, Creuzot-Garcher C, Robichon F, Bron A, Quercia P. Static postural control in children with developmental dyslexia. Neurosci Lett. 2006;403(3):211-215.

18. Kapoula Z, Bucci MP. Postural control in dyslexic and non-dyslexic children. J Neurol. 2007;254(9):1174-1183.

19. Razuk M, Barela JA. Dyslexic children suffer from less informative visual cues to control posture. Res Dev Disabil. 2014;35(9):1988-1994.

20. Gouleme N, Gerard CL, Bui-Quoc E, Bucci MP. Spatial and temporal analysis of postural control in dyslexic children. Clin Neurophysiol. 2015;126(7):1370-1377.

21. British Dyslexia Association. Available from: http://bdadyslexia.org. uk/about-dyslexia/further-information/dyslexia-research-informationhtml. Accessed March 1, 2013.

22. Habib M, Giraud K. Dyslexia. Handb Clin Neurol. 2013;111: 229-235.

23. Martins da Cunhà H, Alves da Silva $\mathrm{O}$. Syndrome de déficience posturale [Postural Deficiency Syndrome]. J Fr Ophtalmol. 1986;9:747-755.

24. Matheron E, Kapoula Z. Vertical heterophoria and postural control in nonspecific chronic low back pain. PLoS One. 2011;6(3):e18110.

25. Matheron E. Hétérophories verticales en vision de loin et troubles posturaux. In: Lacour M, editor. Posture et Equilibre. Nouveautés conceptuelles, instrumentales et cliniques [Vertical Heterophorias in distance vision and postural disorders from the book Posture and Equilibrium. Conceptual, instumental, and clinical novelties]. Marseille: Solal Edition; 2001:157-163.

26. Quercia P, Seigneuric A, Chariot S, et al. Ocular proprioception and developmental dyslexia. Sixty clinical observations. J Fr Ophtalmol. 2005;28(7):713-723.

27. Quercia P, Seigneuric A, Chariot S, Bron A, Creuzot-Garcher C, Robichon F. Proprioception changes induced by prismatic glasses wear in children suffering from developmental dyslexia. $\mathrm{JFr}$ Ophtalmol. 2007; 30(4):380-389. 
28. Vieira S, Quercia P, Michel C, Pozzo T, Bonnetblanc F. Cognitive demands impair postural control in developmental dyslexia: a negative effect that can be compensated. Neurosci Lett. 2009;462(2):125-129.

29. Quercia P, Demougeot L, Dos Santos M, Bonnetblanc F. Integration of proprioceptive signals and attentional capacity during postural control are impaired but subject to improvement in dyslexic children. Exp Brain Res. 2011;209(4):599-608.

30. Scheiman M, Wick B. Clinical Management of Binocular Vision, Heterophoric, Accommodative and Eye Movement Disorders. Philadelphia: Lippincott; 1994:405-440.

31. Ecalle J. Timé-3. Evaluation in reading: preliminary study for the development of a new word recognition test. ANAE. 2004;79:296-304.

32. Odedys2. Cogni-Sciences. Université de Grenoble. 2005. Available from: http://www.cognisciences.com/

33. Casillas Casillas E, Rosenfield M. Comparison of subjective heterophoria testing with a phoropter and trial frame. Optom Vis Sci. 2006; 83:237-241.

34. Spielmann A. Cyclotorsions. J Fr Ophtalmol. 2002;25(9):959-967.

35. Tollefson MM, Mohney BG, Diehl NN, Burke JP. Incidence and types of childhood hypertropia: a population-based study. Ophthalmology. 2006;113(7):1142-1145.

36. Ohtsuki H, Hasebe S, Kono R, Yamane T, Fujiwara H, Shiraga F. Large Bielschowsky head-tilt phenomenon and inconspicuous vertical deviation in the diagnostic positions in congenital superior oblique palsy. Am J Ophthalmol. 2000;130(6):854-856.

37. Marino A, Quercia P. Vers une orthodontie neuro-sensorielle. Posturologie clinique: Dysfonctions motrices et cognitives. [Neuro-sensory Orthodontia in Clinical Posturology: Motor and Cognitive dysfunction.] Paris: Masson; 2007:226-232.

38. Hartmann F, Cucchi G. Les dysfonctions cranio-mandibulaires: Nouvelles implications médicales. [Cranial-mandibular dysfunctions: New medical implications.] Paris: Springer-Verlag; 1993.

39. Trulsson M, Francis ST, Bowtell R, McGlone F. Brain activations in response to vibrotactile tooth stimulation: a psychophysical and fMRI study. J Neurophysiol. 2010;104(4):2257-2265.

40. Villeneuve PH. Traitement postural et orthèse podale: mécanique ou informative? [Postural treatment and pedal orthosis] In: Weber B, Villeneuve PH, editors. Pied, équilibre et traitements posturaux. Paris: Masson; 2003:93-103.

41. Kushner BJ, Hariharan L. Observations about objective and subjective ocular torsion. Ophthalmology. 2009;116(10):2001-2010.

42. Lefèvre F, Leroy K, Delrieu B, Lassale D, Péchereau A. Study of the optic nerve head-fovea angle with retinophotography in healthy patients. J Fr Ophtalmol. 2007;30(6):598-660.

43. Quercia P. Réalisation de la prescription prismatique et suivi chez 1'enfant dyslexique. [Guide to Prismatic Prescription and follow-up for the dyslexic child.] Les Cahiers d'Ophtalmologie. 2008;124:9-14.

44. Quercia P, Chariot S, Seigneuric A, et al. Developmental dyslexia: visual abnormalities during ocular rotation. In: Investigative Ophthalmology \& Visual Science - Special Issue for ARVO (Association for Research in Vision and Ophthalmology); 2005; Fort Lauderdale, USA.

45. Van Rijn LJ, ten Tusscher MP, de Jong I, Hendrikse F. Asymmetrical vertical phorias indicating dissociated vertical deviation in subjects with normal binocular vision. Vision Res. 1998;38(19):2973-2978.

46. Wahlberg-Ramsay M, Nordström M, Salkic J, Brautaset R. Evaluation of aspects of binocular vision in children with dyslexia. Strabismus. 2012;20(4):139-144.

47. Tiadi A, Seassau M, Bui-Quoc E, Gerard CL, Bucci MP. Vertical saccades in dyslexic children. Res Dev Disabil. 2014;35(11):3175-3181.

48. Schreiber K, Crawford JD, Fetter M, Tweed D. The motor side of depth vision. Nature. 2001;410(6830):819-822.

49. Minken AW, Van Gisbergen JA. A three-dimensional analysis of vergence movements at various levels of elevation. Exp Brain Res. 1994; 101(2):331-345.

50. Taylor MJ, Roberts DC, Zee DS. Effect of sustained cyclovergence on eye alignment: rapid torsional phoria adaptation. Invest Ophthalmol Vis Sci. 2000;41(5):1076-1083.
51. Schor CM, Maxwell JS, McCandless J, Graf E. Adaptive control of vergence in humans. Ann N Y Acad Sci. 2002;956:297-305.

52. Van Rijn LJ, Van der Steen J, Collewijn H. Instability of ocular torsion during fixation: cyclovergence is more stable than cycloversion. Vision Res. 1994;34(8):1077-1087.

53. Enright JT. Unexpected role of the oblique muscles in the human vertical fusional reflex. J Physiol. 1992;451:279-293.

54. Henson DB, Dharamshi BG. Oculomotor adaptation to induced heterophoria and anisometropia. Invest Ophthalmol Vis Sci. 1982;22(2): 234-240.

55. Migliaccio AA, Della Santina CC, Carey JP, Minor LB, Zee DS. The effect of binocular eye position and head rotation plane on the human torsional vestibuloocular reflex. Vision Res. 2006;46(16):2475-2486.

56. Quercia P, Feiss L, Michel C. Developmental dyslexia and vision. Clin Ophthalmol. 2013;7:869-881.

57. Roll R, Velay JL, Roll JP. Eye and neck proprioceptive messages contribute to the spatial coding of retinal input in visually oriented activities. Exp Brain Res. 1991;85(2):423-431.

58. Roll JP, Vedel JP, Roll R. Eye, head and skeletal muscle spindle feedback in the elaboration of body references. Prog Brain Res. 1989;80: 113-123 [discussion 57-60].

59. Matheron E, Quercia P, Weber B, Gagey PM. Vertical heterophoria and postural deficiency syndrome. Gait Posture. 2005;21(suppl 1): S132-S133.

60. Available from: http://censtimco.org/wp-content/uploads/2012/10/ Dijon-2012-Stimulation-Cognitive-Actes_communications-affich $\%$ C3\%A9es-1.pdf. Accessed April 15, 2015.

61. Stoodley CJ, Stein JF. Cerebellar function in developmental dyslexia. Cerebellum. 2013;12(2):267-276.

62. Schmahmann JD, Sherman JC. The cerebellar cognitive affective syndrome. Brain. 1998;121(pt 4):561-579.

63. Milder DG, Reinecke RD. Phoria adaptation to prisms: a cerebellar dependent response. Arch Neurol. 1983;40:339-342.

64. Takakusaki K. Neurophysiology of gait: from the spinal cord to the frontal lobe. Mov Disord. 2013;28(11):1483-1491.

65. Viholainen H, Aro M, Ahonen T, Crawford S, Cantell M, Kooistra L. Are balance problems connected to reading speed or the familial risk of dyslexia? Dev Med Child Neurol. 2011;53(4):350-353.

66. Ramus F. Developmental dyslexia: specific phonological deficit or general sensorimotor dysfunction? Curr Opin Neurobiol. 2003;13: 212-218.

67. Bucci MP, Mélithe D, Ajrezo L, Bui-Quoc E, Gérard CL. The influence of oculomotor tasks on postural control in dyslexic children. Front Hum Neurosci. 2014;8:981

68. Rochelle KS, Witton C, Talcott JB. Symptoms of hyperactivity and inattention can mediate deficits of postural stability in developmental dyslexia. Exp Brain Res. 2009;192(4):627-633.

69. Kapoula Z, Matheron E, Demule E, Fauvel C, Bucci MP. Postural control during the Stroop test in dyslexic and non dyslexic teenagers. PLoS One. 2011;6(4):e19272.

70. Bucci MP, Gerard CL, Bui-Quoc E. The effect of a cognitive task on the postural control of dyslexic children. Res Dev Disabil. 2013;34(11): 3727-3735.

71. Barela JA, Dias JL, Godoi D, Viana AR, de Freitas PB. Postural control and automaticity in dyslexic children: the relationship between visual information and body sway. Res Dev Disabil. 2011;32(5):1814-1821.

72. Kapoula Z, Gaertner C, Matheron E. Spherical lenses and prisms lead to postural instability in both dyslexic and non dyslexic adolescents. PLoS One. 2012;7(11):e46739.

73. Matheron E, Kapoula Z. Vertical phoria and postural control in upright stance in healthy young subjects. Clin Neurophysiol. 2008; 119(10):2314-2320.

74. Matheron E, Lê TT, Yang Q, Kapoula Z. Effects of a two-diopter vertical prism on posture. Neurosci Lett. 2007;423(3):236-240.

75. Matheron E, Yang Q, Lê TT, Kapoula Z. Effects of ocular dominance on the vertical vergence induced by a 2-diopter vertical prism during standing. Neurosci Lett. 2008;444(2):176-180. 
76. Clark KA, Helland T, Specht K, et al. Neuroanatomical precursors of dyslexia identified from pre-reading through to age 11. Brain. 2014; 137(pt 12):3136-3141.

77. Ashton JA, Boddy A, Donaldson IM. Input from proprioceptors in the extrinsic ocular muscles to the vestibular nuclei in the giant toad, bufo marinus. Exp Brain Res. 1984;53(2):409-419.

78. Buisseret $P$. Influence of extraocular muscle proprioception on vision. Physiol Rev. 1995;75(2):323-338

79. Hahn N, Foxe JJ, Molholm S. Impairments of multisensory integration and cross-sensory learning as pathways to dyslexia. Neurosci Biobehav Rev. 2014;47C:384-392.

80. Wallace MT, Roberson GE, Hairston WD, Stein BE, Vaughan JW, Schirillo JA. Unifying multisensory signals across time and space. Exp Brain Res. 2004;158(2):252-258.
81. Stevenson RA, Fister JK, Barnett ZP, Nidiffer AR, Wallace MT. Interactions between the spatial and temporal stimulus factors that influence multisensory integration in human performance. Exp Brain Res. 2012;219(1):121-137.

82. Gauthier GM, Nommay D, Vercher JL. The role of ocular muscle proprioception in visual localization of targets. Science. 1990; 249(4964):58-61.

83. Balslev D, Newman W, Knox PC. Extraocular muscle afferent signals modulate visual attention. Invest Ophthalmol Vis Sci. 2012;53(11): 7004-7009.

84. Balslev D, Odoj B, Karnath HO. Role of somatosensory cortex in visuospatial attention. J Neurosci. 2013;33(46):18311-18318.

85. Bosse ML, Tainturier MJ, Valdois S. Developmental dyslexia: the visual attention span deficit hypothesis. Cognition. 2007;104(2):198-230.
Clinical Ophthalmology

\section{Publish your work in this journal}

Clinical Ophthalmology is an international, peer-reviewed journal covering all subspecialties within ophthalmology. Key topics include: Optometry; Visual science; Pharmacology and drug therapy in eye diseases; Basic Sciences; Primary and Secondary eye care; Patien Safety and Quality of Care Improvements. This journal is indexed on

Submit your manuscript here: http://www.dovepress.com/clinical-ophthalmology-journal

\section{Dovepress}

PubMed Central and CAS, and is the official journal of The Society of Clinical Ophthalmology (SCO). The manuscript management system is completely online and includes a very quick and fair peer-review system, which is all easy to use. Visit http://www.dovepress.com/ testimonials.php to read real quotes from published authors. 